\title{
An Approach in Teaching Reading for Down Syndrome Children
}

\author{
Rahmah Lob Yussof, Wan Syaqira Wan Mohd Anuuar, Riaza Mohd Rias, Hafiza Abas, and Anidzan \\ Ariffin
}

\begin{abstract}
Teaching approach for down syndrome (DS) Children is not the same as teaching the normal ones. The DS children require special teaching approach and attention from their teachers. Indeed, it has been proven that DS children are able to learn but in a more specific way. Until now, there have not been advanced teaching tools that are suitable for DS children to use in their learning process. This paper presents a preliminary study that was conducted at Kiwanis Klang Centre, which enrols only DS children to: 1) investigate the method of learning reading among DS children and 2) examine the type of learning tools used during the learning session. The procedures used for this preliminary study were divided into two types: interviews with teachers and observation on DS children during their reading session. The materials used in the learning session were paper and flash cards. It was found that these DS children used simple words and images during the learning session. Even though they are learning in traditional ways, teachers affirmed that these DS children were able to handle and play with gadgets such as smart phones and tablets which belong to their parents just like other normal children.
\end{abstract}

Index Terms - Down syndrome, sight words, flash cards, reading, mobile based.

\section{INTRODUCTION}

DS Children are commonly known for their genetic disorder due to the existence of third copy chromosome 21. Due to this genetic disorder, DS children are facing physical and cognitive impairment. The degree of mental impairment is variable, ranging from mild (IQ: 50-70) to moderate (IQ: 35-50), and only occasionally to severe (IQ: 20-35) (PEDIATRIC, 2001). PEDIATRIC (2001) also stated that DS children whose ages range from 1 to 5 are expected to undergo special guidance in early intervention, such as physical, occupational and speech therapies in the preschool program.

Back in 1980, there was a father of a DS girl who described that he had discovered that his daughter was able to learn to read at the age of three years old. He taught her to read by using flash cards and finally when she was twelve years old, she was enrolled in a mainstream school and was considered to be exceptionally able for a DS child. The father believed that his daughter's exceptional progress in learning was because of him teaching her to read at the very early age [1]. From this report, researchers made further investigations on learning capability in reading for DS children and received

Manuscript received March 14, 2015; revised July 23, 2015.

The authors are with Universiti Teknologi MARA, Malaysia (e-mail: rahmah128@pahang.uitm.edu.my,

hafiza.abas@gmail.com, anidzan715@kelantan.uitm.edu.my). significant results

Preliminary study is defined as an initial exploration of issues related to a proposed quality review or evaluation [2]. The aim of this preliminary study is to provide an overview and to establish that the results are relevant for future researches. This paper focuses on results of a preliminary study that was conducted at Kiwanis Klang, a centre for DS children whose ages range from 1 to 6 .

\section{LEARNING STYLES OF CHILDREN WITH DOWN SYNDROME}

The learning styles of DS children can be determined by some of their characteristics such as abstract thinking, attention span and short-term memory [3]. DS children can learn in a variety of ways; either through play time or daily occurrences [4]. Ref. [5] has described a few steps of the learning process for DS children in her study. DS children will:

1) receive information through their natural five sensory organs of sight, hearing, touch, taste and smell. This is known as sensory information.

2) sort and interpret the sensory information such as meaning of specific objects and events that occur. This process is known as perception.

3) store the sensory input perception into their memory.

4) retrieve the knowledge or information from the memory and use it in a different context.

Ref. [4] also affirmed that it is necessary that DS children practice what they have learned in order to acquire more new abilities in gaining new skills. This indicates that after they have acquired the new knowledge or information, they need to retrieve and reuse the knowledge again and again. Eventually, they will be able to acquire new skills. The earlier the children master these new skills, the more advantageous that they will be compared to others. This method is commonly known as early intervention that focuses on young children.

\section{READING ABILITY AMONG CHILDREN WITH DOWN SYNDROME}

Learning to read is a basic skill that everybody should acquire sufficiently. This literacy skill is increasingly important as the children grow up. Unfortunately, about 30 years ago, DS individuals were not encouraged in learning to read as the societies had believed they had no abilities to read and it was also thought that it would be useless for such people to learn reading. [6]. For educational purpose, reading is compulsory for every child, regardless of his/her ability. Reading is one step ahead in education because, without 
reading skills, children will not be able to cope with challenges in their future life. Unfortunately, disabled children have difficulties in acquiring reading skill [7].

Even though the DS children have such difficulty, they are encouraged to read in order to help them to be able to communicate with other people. These DS children have difficulties in speaking or communicating due to their cognitive impairment. Thus, by teaching them to read, they will be able to overcome this problem. [8], [9]. Once the DS children start learning to acquire new skills, they will practice and use the skills acquired in the next learning session because they want to enhance the accuracy of their skills and be able to take part in communications [4]. Furthermore, their ability to read will be the initial step before they can move on to sessions on vocabulary and language development [10].

\section{PRELIMINARY STUDY}

An interview and observation were conducted at Kiwanis Klang, Selangor, Malaysia. Kiwanis Klang is one of the centres for DS children, owned by Kiwanis, a non-governmental organisation. This centre focuses on early intervention for DS children whose ages range from 2 to 6 . The purposes of this preliminary study are to investigate the method of learning to read among DS children and to examine the type of learning tools used during the learning sessions.

\section{A. Interviews}

The main purpose of this interview is to obtain information of how DS children learn during their reading sessions. The reading sessions were conducted by two experienced teachers; Teacher 1 and Teacher 2. The two teachers were interviewed.

Teacher 1 has 27 years of experience in teaching many types of disabled children in special schools. She stated that the teaching approach used at Kiwanis Klang Centre was based on a book "A Curriculum Guide for Teaching Young Mentally Handicapped", written by Robert Deller. The book guides teachers for teaching disabled children in all aspects. Teacher 1 also stated that according to Deller, there are a few steps that a child needs to accomplish accordingly before entering the phase of learning to read. The child should be:

- Able to recognize and show objects

- Able to match colours and objects

- Able to sort objects based on their categories

- Able to match pictures

- Able to match alphabets

- Able to sort shapes

- Able to sort pictures

The progress of the DS children varies from one another. There were DS children who were able to accomplish every task in a short period, and others took months to accomplish every task. Every task is done individually, and every progress is recorded in the child's special record book. In the learning process of reading, there are tasks that these DS children need to follow step by step. Teacher 1 also stated the DS children's progress depends on both parties, teachers and parents or guardian. One of the factors of the slow progress in the DS children's learning process is uncommitted parents or guardian. At the end of the interview session, Teacher 1 asserted that, "If these children have been exposed to early intervention since they were young, they could have accomplished much better even before entering mainstream schools. There were children that were able to accomplish all tasks in four years, which is considered a rapid progress. As for me, these children are just like normal children. It is just that they are slower mostly in everything. So, we need to help these children for their better future."

Teacher 2 has an experience of 24 years in teaching disabled children. She said that, even though, the centre did not provide any teaching materials in the form of advanced teaching devices, these children have been exposed to smart phones since they were young. They have been playing games in the smart phones which belong to their parents. She further stated that, "Unfortunately, at this centre, we only use traditional methods to teach these children in most tasks. We have few computers at this centre, but we rarely use them for learning purposes."

Based on this interview with the two experienced teachers, there are few things that were discovered and can be highlighted. It was found that DS Children were able to learn with specific methods adopted from Robert Deller's book. Furthermore, there are a few conditions that these DS children need to accomplish before they start the reading session. It was also found out that these DS children were also capable in handling devices like smart phones and tablets.

\section{B. Observation}

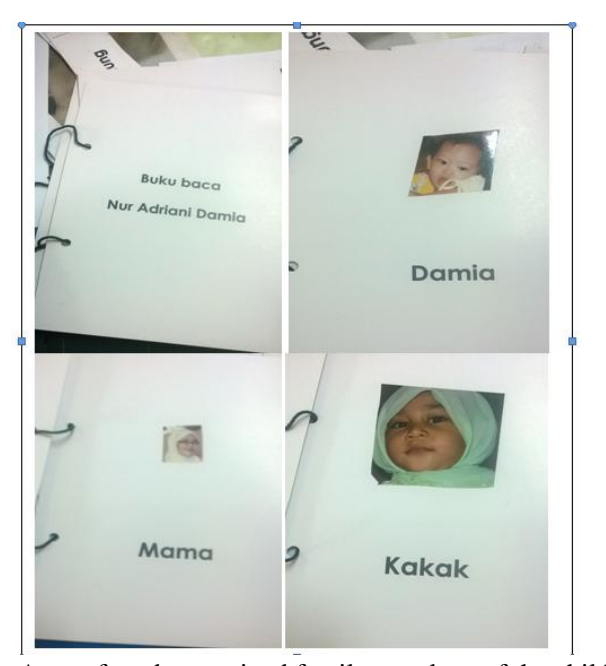

Fig. 1. A set of cards contained family members of the child.

An observation was also done at the Kiwanis Klang Centre. However, this observation only focused on DS children's reading activities and the teaching materials which the centre provided for the children. The following description gives an insight of how the DS children at Kiwanis Klang Centre learned during the reading session.

The teachers started the activity by presenting a set of manila cards that contained the pictures and names of the family members as shown in Fig. 1. Fig. 1 shows a set of cards of Damia's family members. Before the activity started, the teacher would ask the parents to submit pictures of four family members who were closest to the child and those whom the child is familiar with. The members are usually the mother, father, sister or brother and a grandmother. The cards were shown to the child during the session. The teacher will read out the name of the family members loudly while pointing at 
their pictures one by one. After five minutes of repeating the name of the family members, the teacher would cover the names of the family members and asked the child what their names were while pointing at each picture one after another at a time. The activity continued where the teacher gave the child another set of pictures of the same family members, but this time without their names attached. The child was requested to match the pictures with the names. The last step is a recall, where the teacher would say out the name of each of the family members and ask the child to pick up a picture of each and post it in a small mailbox. When the child has completed this family member activity, they will then proceed to learn other words with the same steps as mentioned above.

Fig. 1 shows a set of cards of Damia's family members consisting of Damia, her mother, her sister and her grandmother. The teacher made two sets of cards that comprise the same family members. One set will be kept by the centre while the second set will be given to Damia's parents. The purpose of making one copy for the parents is because they are encouraged to teach their children on their own whenever they have time at home. This method can make the child learn faster and effectively. This teaching approach is in accordance with the spatial contiguity principle and sight word method. It can be seen here that the activities stated above follows spatial contiguity principle; each card contains a word and an image that corresponds to one another in one presentation while the sight word is a word that the learner is familiar with, as indicated in the family cards. Here, Damia has just accomplished all the tasks and steps stated, and she was ready to start her first task of the reading activity.

Fig. 2 shows a reading activity that is conducted individually between the teacher and the learner. This is done so that the teacher can give full attention to each one of the DS children at a time. Moreover, the reading activity is done in a private corner to avoid other disturbance that may distract the child's attention. At the end of the activity, the child's progress is recorded in his/her record book accordingly.

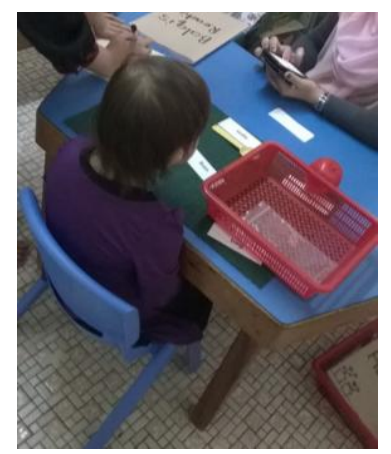

Fig. 2. A learning activity between a child and a teacher.

\section{FINDINGS}

The information gathered from the interviews and observations was analyzed. It was found that this centre uses traditional methods in teaching DS children because there have not been teaching applications or devices existed so far that are appropriate for DS children. Even though this centre does not provide advanced devices for learning purposes, these DS children have been exposed to mobile devices by their families. They are capable of handling and playing with touch screen devices just like typically other normal developing children.

It was discovered that the centre did not use or apply any applications or software for DS children during their learning activities. The teachers stated that the applications and software are not compatible with the ability of the DS children. Hence, it will be a waste of time to encourage them to use the applications and software for the learning purposes. However, it was also found out that these DS children were completely able to play games that were available in their parents' smart phones and tablets. Since they were aware of and have already had experiences in handling smart phones and tablets, this trait would ease us in introducing a new application for their learning purposes.

\section{DISCUSSION}

Diverse learners (Autism, DS, and Dyslexia) have difficulty learning with the traditional pedagogies used in teaching [11]. Children with disabilities in Malaysia attend to mainstream schools that provide general special education that is not according to their capabilities and limitations in learning.

Teaching DS children to read is different from teaching typically normal developing children. Their mental age usually is younger than their exact age. DS children have a range of IQ level where there are some who are unable to speak and communicate while there are some of them who are intelligent and learn well [12].

DS children hardly pay attention to the activities that seem uninteresting to them. If the information presented only in oral form, it is even more difficult for them to concentrate [6]. This is known as attention span which means they can easily get distracted by their surroundings. DS children likewise bear difficulties in speaking and communication due to their cognitive impairment. Nevertheless by teaching them to read, they will be able to overcome these problems. To help and support these DS children in learning regardless of the context, the design and presentation of teaching aids and materials should be according to their style of learning. Traditional methods teach typically developing children are not suitable for DS children. Besides, there are only few researchers who have conducted studies on reading abilities among DS children [13].

The DS children start learning from a whole recognizable words called sight words, and as they progress, then they will learn to decode the words. This is because they are visual learners who are only attracted to a visual form of presentations. There are few benefits when sight word technique is implemented. Such as the confidence level of reading skills in student will constantly increase, their daily routine skills also will improve, and negative emotional level can be lower when they are engaging with learning to read environment [14]. There are few researches have conducted on computer-based sight word intervention for children with disabilities, but there is no research specifically focused on DS children in early reading skills. A study focused on a student with Autism engaging with computer-based sight word reading intervention, have found that the student successfully able to learn 25 words in just 16 sessions [15]. 
Presentation in a visual form for example, flashcard, is proven able to attract children with disabilities attention and it is easier to remember the outcome of the learning [16]. DS children are known for their strength in visual-spatial memory compared to audio-verbal memory [17]. This method is also illustrated by Robert Deller in his book. Furthermore, teachers had improved the method by using traditional flash cards as part of the teaching tools in reading. Teachers at Kiwanis Klang Centre have taught DS children from the range 3 to 6 years in various skills as mentioned and how these skills have aided DS children during their elementary schools. They were able to cope with school because they have skills taught at the centre.

Since nowadays technologies such as smartphones, tablet and personal computer have been exposed to these young children including DS children, they have basic knowledge on how to handle these gadgets. Beside, the implementation of electronic devices such as smartphones and tablets may increase these children with disabilities in learning and attention [18]. There was a study focused on mobile application development that can support DS children in learning [12]. However, this study only focused on learning mathematics. The application should correspond to the mental age of these DS children in order for them to learn properly without boredom and frustration. Considering the children have been exposed to information technology gadgets, it is believed that these DS children are capable to explore new things or devices which will eventually improve their understanding skills [12]. When we acknowledge how these DS children ways to learn, then we need to apply suitable design principle that relevant to these children. Spatial contiguity principle, one of Mayer's design principle is found to be able to show a significant gain in learning effectively and efficiently [19].

Reading is obligatory for every child despite their disabilities. Reading is one step ahead for education because without reading skills, they will not be able to cope with challenges in the future. Reading will be the initial step before vocabulary and language development in DS children and the future [20].

\section{CONCLUSION}

Teachers at Kiwanis Klang Centre are using traditional flash cards for teaching DS children in reading. Since DS children are exposed and use to deal with mobile technology such as tablets; thus, there is a need to propose a specific teaching aid to support them in learning to read. In the future study, researchers will focus on developing a mobile application for DS children to learn to read.

\section{ACKNOWLEDGMENT}

This research is sponsored by FRGS from Ministry of Higher Education (MOHE) and Universiti Teknologi MARA (UiTM).

\section{REFERENCES}

[1] S. J. Buckley, G. Bird, "Teaching children with down syndrome to read," Down Syndrome Research and Practice, vol. 1, no. 1, pp. 34-39, 1993.

[2] L. Harvey. (2014). Analytic quality glossary, quality research international. [Online]. Available: http://www.qualityresearchinternational.com/glossary

[3] J. M. Ortega-Tudela and C. J. Gomez-Ariza, "Computer-assisted teaching and mathematical learning in Down syndrome children," Journal of Computer Assisted Learning, vol. 22, pp. 298-307, 2006.

[4] D. Mara and E. L. Mara, "Characteristics of learning process at children with down syndrome," Social and Behavioural Sciences, vol. 30, pp. 73-78, 2011.

[5] R. L. Yussof, "Perisian kursus multimedia untuk murid sindrom down (MEL-SindD)," Thesis PhD Universiti Kebangsaan Malaysia (UKM), 2010.

[6] B. P. M. Haro, P. C. Santana, and M. A. Magana, "Developing reading skills in children with down syndrome through tangible interfaces," in Proc. the 4th Mexican Conference on Human-Computer Interaction, pp. 28-34, México Interacción Humano-Computadora, 2012.

[7] M. Watson, C. Fore, and R. T. Boon, "Corrective feedback of oral decoding errors for diverse learners with reading disabilities: The effects of two methods on reading fluency," International Journal of Special Education, vol. 24, no. 1, pp. 20-31, 2009.

[8] J. Kotlinski and S. Kotlinski, "Teaching reading to develop language. down syndrome news and update," 2002.

[9] T. N. S. T. Paris and R. L. Yussof, "Preliminary study of early reading courseware for down syndrome children," Social and Behavioral Sciences vol. 35, pp. 113-120, 2011.

[10] (2014). Down syndrome education international. Development and Learning. [Online]. Available http://www.dseinternational.org/en-gb/about-down-syndrome/develop ment

[11] C. M. Shepherd and N. Alpert, "Engaging diverse learners through new technologies," in Proc. GHTC, pp. 53-56.

[12] W. F. W. Ahmad, H. N. I. Muddin, and A. Shafie, "Number skills mobile application for down syndrome children," 2014.

[13] K. B. Naess, M. Melby-Lervag, C. Hulme, and S. H. Lyster, "Reading skills in children with down syndrome: A meta-analytic review," Research in Developmental Disabilities, vol. 33, pp. 737-747, 2011.

[14] S. Bliss, C. H. Skinner, and R. Adams, "Enhancing an English language learning fifth-grade student's sight-word reading with a time-delay taped-words intervention," School Psychology Review, vol. 35, pp. 663-670, 2006

[15] J. S. Yaw, C. H. Skinner, J. Parkhust, C. M. Taylor, J. Booher, and K Chambers, "Extending research on a computer-based sight word reading intervention to a student with Autism," J Behav Educ, vol. 20, pp. 44-54, 2011.

[16] eReadingpro. (2014). Reading and the visual learner. [Online]. Available: http://www.ereadingpro.com/visual-learner.htm

[17] J. Feng, J. Lazar, L. Kumin, and A. Ozok, "Computer usage by young individuals with down syndrome: An exploratory study. Published in ASSETSO8," in Proc. the 10th International ACM SIGACCESS Conference on Computers and Accessibility, pp. 35-42, ACM, 2008.

[18] A. Fernandez-Lopez, M. J. Rodriguez-Fortiz, M. L. Rodriguez-Almendros, and M. J. Martinez-Segura, "Mobile learning technology based on iOS devices to support students with special education needs," Computer \& Education, vol. 61, pp. 77-90, 2012.

[19] S. Paek, D. Hoffman, and A. Saravanos, "Spatial contiguity and implicit learning in hypertext," in Proc. the 21st ACM conference on Hypertext and hypermedia, ACM, 2010, pp. 291-292.

[20] Down Syndrome Education International. (2014). Development and Learning. [Online]. Available:

http://www.dseinternational.org/en-gb/about-down-syndrome/develop ment

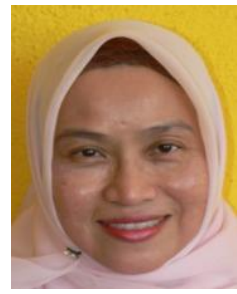

Rahmah Lob Yussof was born in Dungun, Terengganu Malaysia on July 29, 1961. She finished her PhD at Universiti Kebangsaan Malaysia (UKM) in 2010. She is now a senior lecturer at Universit Teknologi MARA Pahang, Malaysia. Her research areas include mobile based, blended learning, multimedia etc. 